\title{
Dynamic solidification of Sn-38.1\% Pb eutectic alloy within ultrasonic field
}

\author{
ZHAI Wei, HONG ZhenYu, XIE WenJun \& WEI BingBo* \\ Department of Applied Physics, Northwestern Polytechnical University, Xi'an 710072, China
}

Received March 22, 2010; accepted June 9, 2010; Published online November 1, 2010

\begin{abstract}
The dynamic solidification of $\mathrm{Sn}-38.1 \% \mathrm{~Pb}$ eutectic alloy within an ultrasonic field is investigated at a frequency of $35 \mathrm{kHz}$. As the sample height $H$ is reduced, the effect of ultrasound on macrosegregation becomes more prominent, and the volume fraction of spherical eutectic cells increases correspondingly. When $H$ equals the wavelength $\lambda$ in liquid alloy, the introduction of ultrasound enlarges the distribution region of the primary $(\mathrm{Sn})$ phase, but reduces the domains of the Sn-Pb eutectic and primary $(\mathrm{Pb})$ phases. Meanwhile, a "dendritic-equiaxed" structural transition occurs in the primary ( $\mathrm{Sn}$ ) phase, and its grain size is significantly reduced within the ultrasonic field. Once $H$ decreases to $\lambda / 2$ and $\lambda / 4$, the ultrasonic field promotes crystal nucleation and suppresses further undercooling of the bulk liquid alloy. Theoretical analyses indicate that the local high pressure induced by the cavitation effect and the stirring effect due to acoustic streaming are the main factors dominating the eutectic growth mechanism during dynamic solidification.
\end{abstract}

ultrasonic field, eutectic growth, spherical eutectic cell, cavitation effect, acoustic streaming

Citation: Zhai W, Hong Z Y, Xie W J, et al. Dynamic solidification of Sn-38.1\% Pb eutectic alloy within ultrasonic field. Chinese Sci Bull, 2011, 56: 89-95, doi: $10.1007 / \mathrm{s} 11434-010-4084-5$

The dynamic solidification of liquid metals and alloys within an ultrasonic field has been extensively studied in the field of material physics [1-8]. The propagation of the ultrasonic wave not only transmits acoustic energy into the liquid alloy but also brings about such nonlinear effects as acoustic cavitation and streaming, which influences the microstructures of solidified alloys and improves their properties for the intended application [1-4]. The most beneficial uses of ultrasound in solidification include reducing grain size [4-6], degassing melts and suppressing shrink pipes $[8,9]$. Campell [2] reviewed the effects of various kinds of vibration on solidification, and summarized that sound intensity, frequency and vibration mode are the three key factors. Nevertheless, another important parameter, the critical size of alloy sample within which ultrasound can function, has been neglected by most researchers. In fact, when an ultrasonic wave travels through a solidifying alloy melt,

*Corresponding author (email: bbwei@nwpu.edu.cn) reflection and transmission always take place because of the existence of the solid-liquid interface. During solidification, the mutual motion between growing solid phases and liquid alloy induces sound attenuation because the propagation distance increases [10]. These result in the weakening of both the cavitation effect and acoustic streaming [11]. As a consequence, the ultrasound is effective only within a limited volume, outside of which the sound intensity is insufficient to affect the solidification process.

In addition, great efforts have been made to investigate dendritic growth in the presence of ultrasonic waves. However, eutectic growth within an ultrasonic field, which involves the nucleation and growth of two or more eutectic phases, is more complicated and requires more in depth investigation. $\mathrm{Sn}-\mathrm{Pb}$ alloy is a typical binary eutectic system with many applications. The main objective of this work is to examine the microstructural transition of the $\mathrm{Sn}-38.1 \% \mathrm{~Pb}$ eutectic alloy along the direction of wave propagation in alloy samples with different heights. The effective domain 
that ultrasound can operate is determined by the variation of microstructural characteristics in different zones of the alloy samples. Finally, the mechanism of $\mathrm{Sn}-\mathrm{Pb}$ eutectic growth within an ultrasonic field is discussed.

\section{Experimental procedure}

The experiments were performed in a solidification apparatus incorporated with an ultrasonic generator. $\mathrm{Sn}-38.1 \% \mathrm{~Pb}$ alloy was prepared from high purity elements of $99.9 \% \mathrm{Sn}$ and $99.9 \% \mathrm{~Pb}$. Three different samples of height $H=\lambda, \lambda / 2$ and $\lambda / 4$ ( $\lambda=66 \mathrm{~mm}$ is the wavelength in liquid alloy) were selected. Each sample was contained in a $\Phi 10 \times 13 \times 80 \mathrm{~mm}$ $\mathrm{Al}$ crucible, and heated by an electrical resistance furnace in an argon atmosphere to prevent oxidization. The melt temperature was monitored by a NiCr-NiSi thermocouple and was recorded by a type 3067 recorder. The cooling curves were measured at both the top and bottom of the $H=\lambda$ and $\lambda / 2$ alloy samples and in the middle of the $H=\lambda / 4$ due to its small height. The vibrating device consists of two parts: a $\mathrm{KNbO}_{3}$ piezoelectric transducer with a resonant frequency of $35 \mathrm{kHz}$ and an emitter with an end plane of $\Phi 9.6 \mathrm{~mm}$. When the melt temperature dropped to $100 \mathrm{~K}$ higher than the $\mathrm{Sn}-\mathrm{Pb}$ eutectic temperature $T_{\mathrm{E}}$, the longitudinal ultrasonic wave was introduced to the alloy melt by the preheated emitter from the top of the sample until it solidified completely. The resonance condition of the acoustic transducer was kept invariant for all the samples, and the sound intensity at the sound source was about $12 \mathrm{~W} / \mathrm{cm}^{2}$.

After the experiments were conducted, the solidified samples were sectioned longitudinally, mounted in epoxy resin, and polished. The microstructures were analyzed with a Zeiss Axiovert 200 MAT optical microscope and a FEI Sirion 200 scanning electron microscope.

\section{Results and discussion}

\subsection{Solidification process of the $H=\lambda$ sample within an ultrasonic field}

Figure 1(a) shows the cooling curves of the $H=\lambda$ sample for the $\mathrm{Sn}-31.8 \% \mathrm{~Pb}$ eutectic alloy. It is apparent that the solidification process is uniform and non-directional. During static solidification, the undercooling $\Delta T$ at the top and bottom of the sample is 9 and $10 \mathrm{~K}$, respectively. When the ultrasonic field is applied, the undercooling at the top of the sample is $5 \mathrm{~K}$, while at the bottom it is $9 \mathrm{~K}$. Obviously, the ultrasonic field reduces the undercooling at the top of the sample, but has almost no influence at the bottom. This suggests that the effect of ultrasound on suppressing undercooling weakens with the wave propagation distance.

Figure 2 presents the growth morphologies of the $\mathrm{Sn}-38.1 \% \mathrm{~Pb}$ eutectic alloy along the sample axis. In the static case, three distinct zones appear from top to bottom in the sample, as shown in Figure 2(a)-(c). In Zone I, a large amount of primary ( $\mathrm{Sn}$ ) phase forms, which is characterized by coarse and well-developed dendrites with an average length of $262 \mu \mathrm{m}$. There is also regular $\mathrm{Sn}-\mathrm{Pb}$ eutectic distributed in the vicinity of the primary ( $\mathrm{Sn})$ phase. The lamellar $\mathrm{Sn}-\mathrm{Pb}$ eutectic microstructure presented in Figure 2(b) is unique to Zone II. The average interlamellar spacing is $2.0 \mu \mathrm{m}$. In Zone III, the microstructure is characterized by large quantities of primary $(\mathrm{Pb})$ dendrites distributed in a $\mathrm{Sn}-\mathrm{Pb}$ eutectic matrix. It should be mentioned that primary $(\mathrm{Pb})$ dendrites become coarser and more densely-packed at the bottom of the sample. The mean length of a primary (Pb) dendritic stalk is $308 \mu \mathrm{m}$, and the secondary arm spacing is $28 \mu \mathrm{m}$. The metallographic measurement results plotted in Figure 3 reveal that Zones I, II, and III take up 22\%, $13 \%$, and $65 \%$ of the total sample height, respectively.

When the ultrasonic field is applied, the alloy sample can again be divided into Zones I', II', and III', as shown in Figure 2(d)-(f), whose height fractions are $51 \%, 6 \%$, and $43 \%$, respectively. In comparison with the corresponding height fractions of the three zones during static solidification, it is found that the ultrasonic field significantly alters the macrosegregation pattern by extending the domain of the primary ( $\mathrm{Sn}$ ) phase, while shortening the domains of the $\mathrm{Sn}-\mathrm{Pb}$ eutectic and primary $(\mathrm{Pb})$ phases. Moreover, an evident microstructural transition also takes place within the ultrasonic field. In Zone $\mathrm{I}^{\prime}$, the primary ( $\mathrm{Sn}$ ) phase forms equiaxed grains, and the average grain size decreases dramatically to $36 \mu \mathrm{m}$. Meanwhile, a lot of spherical eutectic cells are
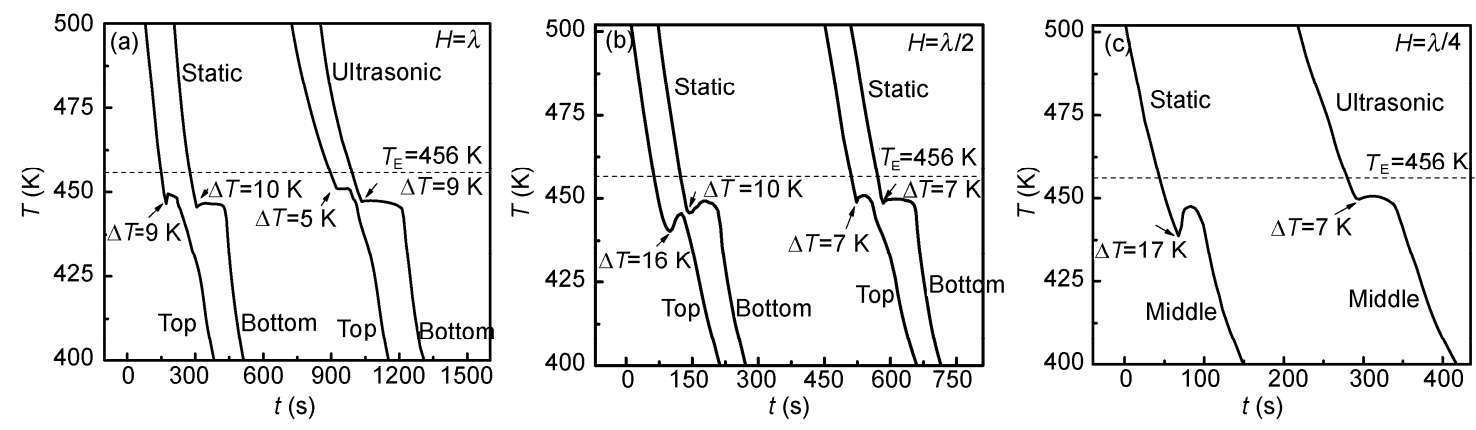

Figure 1 Cooling curves of Sn-38.1\% Pb eutectic alloy. (a) $H=\lambda$; (b) $H=\lambda / 2$; (c) $H=\lambda / 4$. 


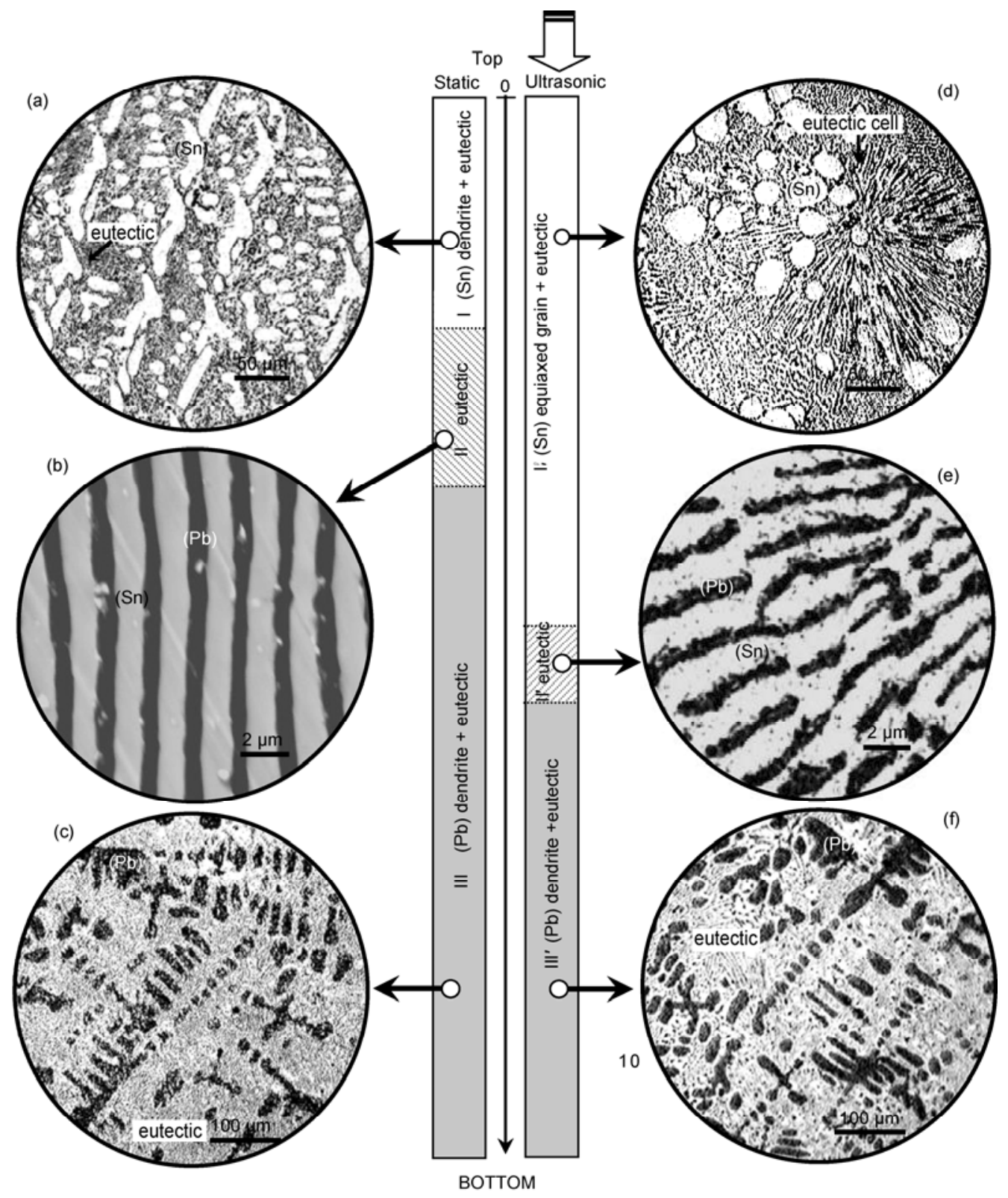

Figure 2 Growth morphology of the $\mathrm{Sn}-38.1 \% \mathrm{~Pb}$ eutectic alloy when $H=\lambda$. (a)-(c) Static; (d)-(f) ultrasonic.

observed in Zone $\mathrm{I}^{\prime}$, as seen in Figure 2(d). In Zone II', the lamellar $\mathrm{Sn}-\mathrm{Pb}$ eutectic that is shown in Figure 2(e) tends to be fragmented or deviate from its original direction of growth, resulting in the degradation of the regularity of the lamellar eutectic structure. This is quite different from that in Zone II of the static case, where the $(\mathrm{Sn})$ and $(\mathrm{Pb})$ phases grow strictly parallel to each other. However, the eutectic interlamellar spacings in the two zones are almost the same. The primary $(\mathrm{Pb})$ phase in Zones III' shows no obvious microstructural variation, and the primary dendritic stalk length, as well as the secondary arm spacing, is very close to that in Zone III. From the above microstructural characteristics, it is clear that the ultrasonic field affects the solidification process of the sample strongly at the top and weakly at the bottom. The change is confined to Zones I'

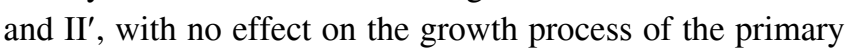
$(\mathrm{Pb})$ phase in Zone III'. This demonstrates that the ultrasonic wave attenuates so sharply in liquid alloy that the effective range of the ultrasonic field is as small as $\lambda / 2$ and far less than $\lambda$ under the present sound intensity.

During the static solidification process of the $\mathrm{Sn}-38.1 \% \mathrm{~Pb}$ eutectic alloy, the $(\mathrm{Pb})$ phase nucleates first throughout the whole alloy melt. Due to its large density, the primary $(\mathrm{Pb})$ phase sinks to the bottom of the alloy sample by Stokes motion to form coarse dendritic structures there. Following the primary $(\mathrm{Pb})$ phase, the $(\mathrm{Sn})$ phase also develops into dendrites from the residual $\mathrm{Sn}$-enriched melt and floats to the top of the sample. Subsequently, the $\mathrm{Sn}-\mathrm{Pb}$ eutectic 
grows from the remaining melt. Thus, the macrosegregation is characterized by the three distinct zones with different microstructures separated in the vertical direction. When the ultrasonic field is applied, the variation of macrosegregation pattern depends mainly on the effective range of the ultrasonic field. In Zone I', the undercooling level is reduced by the ultrasound. This inhibits the growth of the primary $(\mathrm{Pb})$ phase, and leads to the cooperative growth of the $\mathrm{Sn}-\mathrm{Pb}$ eutectic. In contrast, primary $(\mathrm{Pb})$ phase still grows in Zone III' because the undercooling is higher there. Because of the distance between the sound source and Zone III' is greater than the effective range of the ultrasonic field, neither the growth nor the sinking motion of the primary $(\mathrm{Pb})$ phase is influenced by the ultrasound. Similarly, once the primary (Sn) phase appears in Zone III', it floats upwards. As soon as the primary $(\mathrm{Sn})$ phase enters to the effective range of the ultrasonic field, acoustic streaming weakens the buoyancy-driven convection and homogeneously disperses the clouds of formed ( $\mathrm{Sn}$ ) nuclei within the effective region. This is why the macrosegregation patterns can be modified within the $H=\lambda$ sample.

\subsection{Microstructural characteristics of $H=\lambda / 2$ and $\lambda / 4$ samples within the ultrasonic field}

Since the ultrasonic effective length is nearly $\lambda / 2, H$ is reduced to $\lambda / 2$ and $\lambda / 4$ in order to investigate the effect of ultrasound on the $\mathrm{Sn}-\mathrm{Pb}$ eutectic growth mechanism. Figure 1(b) and (c) depict the cooling curves of the $H=\lambda / 2$ and $\lambda / 4$ samples. In the static case, the undercooling $\Delta T$ at the top and bottom of the $H=\lambda / 2$ sample is 16 and $10 \mathrm{~K}$, respectively. In contrast, the undercooling at both positions drops to $7 \mathrm{~K}$ in the presence of ultrasound. Similarly, the bulk undercooling of the $H=\lambda / 4$ sample decreases from $17 \mathrm{~K}$ during static solidification to $10 \mathrm{~K}$ in the ultrasonic field. This confirms that ultrasound promotes crystal nucleation and prevents the bulk undercooling of the alloy melt.

In the case of static solidification, macrosegregation is gradually suppressed as the sample height is reduced. The height fractions $h_{\mathrm{f}}$ of the three kinds of microstructures in each sample are plotted in Figure 3. The solidification microstructures in the $H=\lambda / 2$ sample consist of a large amount of the $\mathrm{Sn}-\mathrm{Pb}$ eutectic and a few small primary $(\mathrm{Pb})$ dendrites. The former occupies about $70 \%$ of the total height of the sample, whereas the latter is distributed within the remaining $30 \%$. With the introduction of ultrasound, the height fraction of the $(\mathrm{Pb})$ dendrites sharply declines to $7 \%$ of the sample height, leaving the $\mathrm{Sn}-\mathrm{Pb}$ eutectic in the remaining $93 \%$. In the static case, the primary $(\mathrm{Pb})$ phase composes only a minor $18 \%$ part of the $H=\lambda / 4$ sample, whereas it disappears in the ultrasonic case, leading to the formation of a $100 \% \mathrm{Sn}-\mathrm{Pb}$ eutectic structure in the solidified sample. Hence, the ultrasound facilitates the suppression of macrosegregation when the alloy sample height is decreased.

Figure 4 displays the $\mathrm{Sn}-\mathrm{Pb}$ eutectic growth morphologies in the $H=\lambda / 2$ alloy sample. In the static case, the $\mathrm{Sn}-\mathrm{Pb}$ eutectic grows in a coupled manner to form a regular lamellar structure and the average interlamellar spacing is about $1.4 \mu \mathrm{m}$. When the ultrasonic field is applied, a large number of spherical eutectic cells are observed closely interconnected in the solidified sample. Figure 4(c) and (d) present the enlarged views of two typical eutectic cells. In Figure 4(c), the spherical eutectic cell consists of anomalous eutectic in the center and lamellar eutectic growing epitaxially. This kind of microstructure reveals that nucleation takes place at the center of the eutectic cell, and the anomalous eutectic structure forms prior to the lamellar eutectic. In the eutectic cell illustrated in Figure 4(d), the lamellar $\mathrm{Sn}-\mathrm{Pb}$ eutectic grows radially from the center to form a spherical shape. The interlamellar spacing of the $\mathrm{Sn}-\mathrm{Pb}$ eutectic within the ultrasonic field is about $5.0 \mu \mathrm{m}$, which is much larger than that during static solidification. Evidently, ultrasonic field brings about a coarsening of the $\mathrm{Sn}-\mathrm{Pb}$ eutectic structure.

The $\mathrm{Sn}-\mathrm{Pb}$ eutectic structure in $H=\lambda / 4$ sample is almost identical to that in $H=\lambda / 2$ sample, which will not be discussed in further detail here.
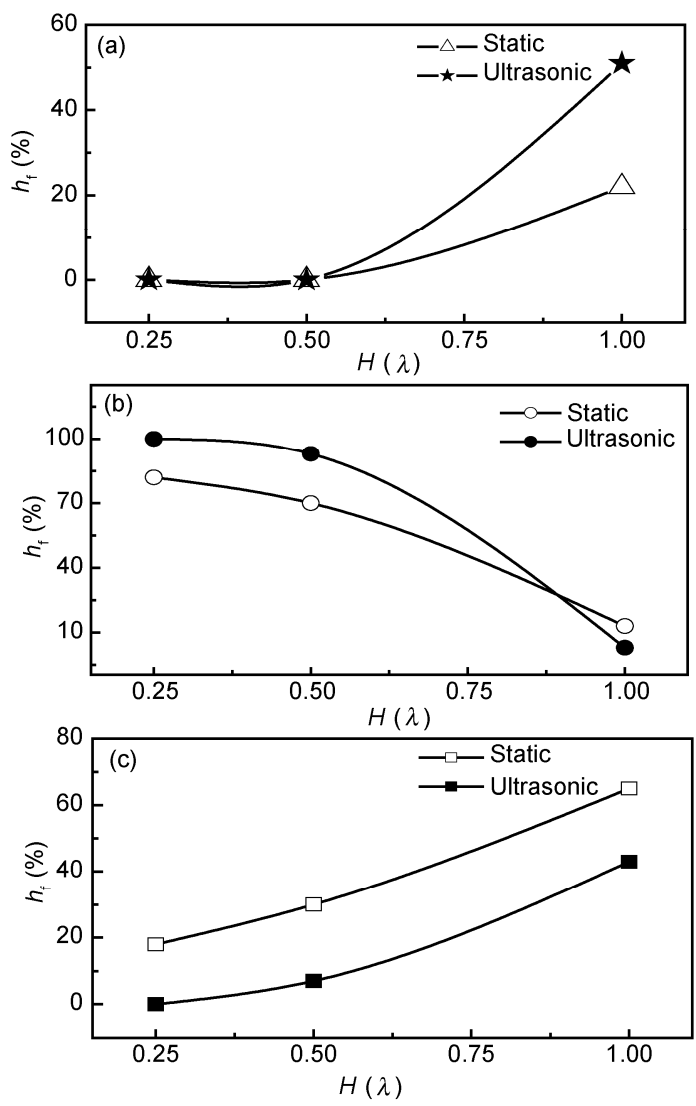

Figure 3 Height fractions of the three kinds of microstructures versus sample height. (a) (Sn) phase+eutectic; (b) eutectic; (c) ( $\mathrm{Pb}$ ) phase+eutectic. 


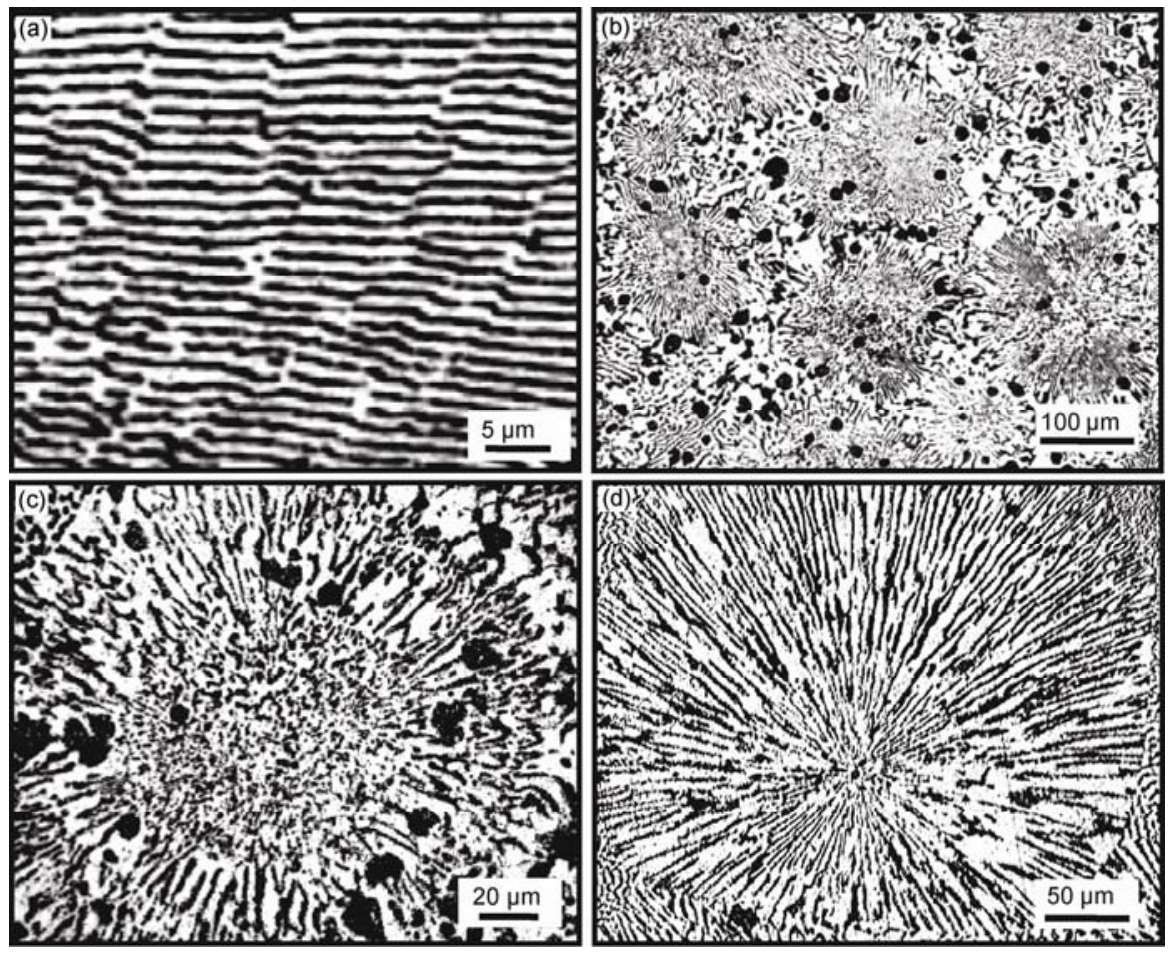

Figure 4 Microstructures of Sn-38.1\% Pb eutectic alloy when $H=\lambda / 2$. (a) Lamellar eutectic structures after static solidification; (b) spherical eutectic cells within ultrasonic field; (c) a spherical grain of anomalous eutectic; (d) a spherical grain of lamellar eutectic structure.

\subsection{Eutectic growth mechanism within the ultrasonic field}

Based on the above microstructural characteristics, it can be concluded that there are two microscopic effects of ultrasound on $\mathrm{Sn}-38.1 \% \mathrm{~Pb}$ alloy: (1) ultrasound promotes crystal nucleation and suppresses bulk undercooling of alloy melt and (2) a large number of spherical eutectic cells form in the presence of ultrasound.

Due to the fact that the bulk undercooling of the alloy melts in the present experiments is relatively small, heterogeneous nucleation is the dominating nucleation mechanism in both static and dynamic cases. According to the classical nucleation theory, the activation energy for nucleation $\Delta G$ is expressed as [12]

$$
\Delta G=\frac{16 \pi \sigma^{3} T_{\mathrm{m}}{ }^{2}}{3 \Delta H_{\mathrm{m}}{ }^{2} \Delta T^{2}} \cdot f(\theta),
$$

where $\sigma$ is the liquid-solid free energy; $T_{\mathrm{m}}$ is the melting temperature; $\Delta H_{\mathrm{m}}$ is the latent heat of fusion, measured in $\mathrm{J} / \mathrm{m}^{3} ; \theta$ is the wetting angle of the solid phase on the heterogeneous nucleus; and $f(\theta)=(2+\cos \theta)(1-\cos \theta)^{2} / 4$ is the wetting angle factor. Solidification occurs only on the condition that at least one nucleus forms in the melt, that is, $I \cdot V \cdot t \geqslant 1$, where $I$ is the nucleation rate, $V$ is the volume of the alloy melt, and $t$ is the solidification time. Take $H=\lambda / 4$ alloy sample as an example. According to its cooling curve in the static case shown in Figure 1(c), $t$ is $32 \mathrm{~s}$. Thus, it can be estimated that $f(\theta) \leqslant 0.05143$ and $\theta \leqslant 43^{\circ}$ during its solidification process.

The cavitation effect is a principal promoter of nucleation. When a strong ultrasonic wave travels through alloy melt, it can generate cavities and small bubbles. These gas bubbles are inherently unstable and can continuously grow by absorbing gas from the surrounding alloy melt. If the sound pressure reaches the threshold value, the bubbles can collapse to a small fraction of their original sizes, generating a huge local transient pressure of up to 1-5 GPa. This, in turn, affects the nucleation process by elevating the local melting temperature.

In addition, although both $\mathrm{Sn}$ and $\mathrm{Pb}$ metals are purified before experimentation, it is impossible to avoid solid impurities within alloy melts. As the ultrasonic wave propagates, the wetting status between these heterogeneous solid particles and alloy melt can be greatly improved by decreasing the wetting angle between the crystal embryos and impurity particles. This provides potential heterogeneous nucleation sites and initiates solidification at small undercooling values.

The relationship between pressure $P$ and melting temperature $T_{\mathrm{m}}$ can be expressed by the Clausius-Clapeyron equation [12]:

$$
T_{\mathrm{m}}=T_{\mathrm{E}}+\frac{T_{\mathrm{E}} \Delta V}{\Delta H_{\mathrm{m}}}\left(P-P_{0}\right),
$$

where $T_{\mathrm{E}}$ is the melting point of the $\mathrm{Sn}-38.1 \% \mathrm{~Pb}$ eutectic 
alloy at the atmospheric pressure $P_{0}$, and $\Delta V$ is the volume change during the liquid-to-solid transformation. The increased local undercooling $\Delta T_{\text {Local }}$ induced by local high pressure is illustrated in Figure 5(a). Assuming a high local pressure of $1-5 \mathrm{GPa}$ is produced by the cavitation effect, $\Delta T_{\text {Local }}$ is raised by $29-145 \mathrm{~K}$, which further changes the activation energy for nucleation. The nucleation activation energies of $(\mathrm{Sn})$ and $(\mathrm{Pb})$ phases in $H=\lambda / 4$ alloy sample are calculated based on eq. (1) through eq. (2) with respect to pressure and wetting angle. The physical parameters used in the calculations are derived from [13], and listed in Table 1. It can be seen clearly in Figure 5 (b) and (c) that the activation energies of the $(\mathrm{Sn})$ and $(\mathrm{Pb})$ phases decrease with the increase of the local pressure and decrease of the wetting angle. At a fixed wetting angle, the local GPa-magnitude pressure reduces the activation energies of both phases by two orders of magnitude. This suggests that cavitation sites are favorable locations for nucleation. On the other hand, as the wetting angle varies from $43^{\circ}$ to $1^{\circ}$, the nucleation activation energies of the two eutectic phases are lowered by a remarkable six orders of magnitude. The reduction of the nucleation activation energy indicates the promotion of nucleation in the alloy melt. Therefore, the decrease of the wetting angle and the local high pressure produced by the cavitation effect are the two main reasons for the inhibition of bulk undercooling.

During the $\mathrm{Sn}-\mathrm{Pb}$ eutectic growth process within the ultrasonic field, both temperature and concentration fields show spatial symmetry because of the stirring effect caused by acoustic streaming. Once nucleation takes place at the cavitation sites, anomalous eutectic structures develop in their vicinity due to the high local undercooling $[14,15]$. Furthermore, the cavitation sites (i.e., nucleation sites) always acts as center points of the circulation flow in the liquid adjacent to the crystals [16], which facilitates radial symmetry of temperature, concentration, and flow fields, and ensures symmetry of the solid-liquid interface in three dimensions. Subsequently, owing to the rapid release of latent heat, the lamellar eutectic grows epitaxially from the anomalous eutectic, leading to the formation of a spherical eutectic cell shown in Figure 4(c). In addition, if eutectic growth is stimulated by heterogeneous nuclei, under the combined effects of small undercooling and symmetrical concentration and temperature distribution, the lamellar eutectic comes out from the center to form a regular spherical

Table 1 Physical parameters in the calculations [13]

\begin{tabular}{cc}
\hline Physical parameter & Value \\
\hline Eutectic temperature $T_{\mathrm{E}}(\mathrm{K})$ & 456 \\
Latent heat of fusion of $(\mathrm{Sn})$ phase $\Delta H_{\mathrm{m}-\mathrm{Sn}}\left(\mathrm{J} / \mathrm{m}^{3}\right)$ & $4.41 \times 10^{8}$ \\
Latent heat of fusion of $(\mathrm{Pb})$ phase $\Delta H_{\mathrm{m}-\mathrm{Pb}}\left(\mathrm{J} / \mathrm{m}^{3}\right)$ & $3.21 \times 10^{8}$ \\
Volume change of $(\mathrm{Sn})$ phase $\Delta V_{\mathrm{Sn}}(\%)$ & 2.3 \\
Volume change of $(\mathrm{Pb})$ phase $\Delta V_{\mathrm{Pb}}(\%)$ & 3.5 \\
L/S interfacial energy of $(\mathrm{Sn})$ phase $\sigma_{\mathrm{Sn}}\left(\mathrm{J} / \mathrm{m}^{2}\right)$ & $5.8 \times 10^{-2}$ \\
L/S interfacial energy of $(\mathrm{Pb})$ phase $\sigma_{\mathrm{Pb}}\left(\mathrm{J} / \mathrm{m}^{2}\right)$ & $4.3 \times 10^{-2}$ \\
\hline
\end{tabular}
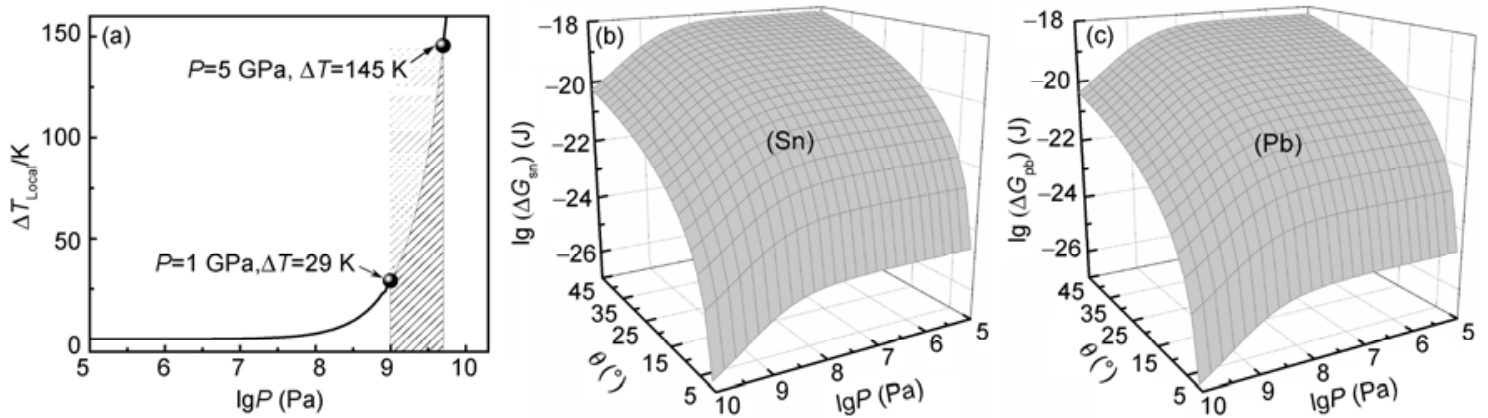

Figure 5 Local undercooling and nucleation activation energy of $\mathrm{Sn}-38.1 \% \mathrm{~Pb}$ alloy. (a) Local undercooling versus pressure; (b) nucleation activation energy of ( $\mathrm{Sn})$ phase versus pressure and wetting angle; (c) nucleation activation energy of $(\mathrm{Pb})$ phase versus pressure and wetting angle.

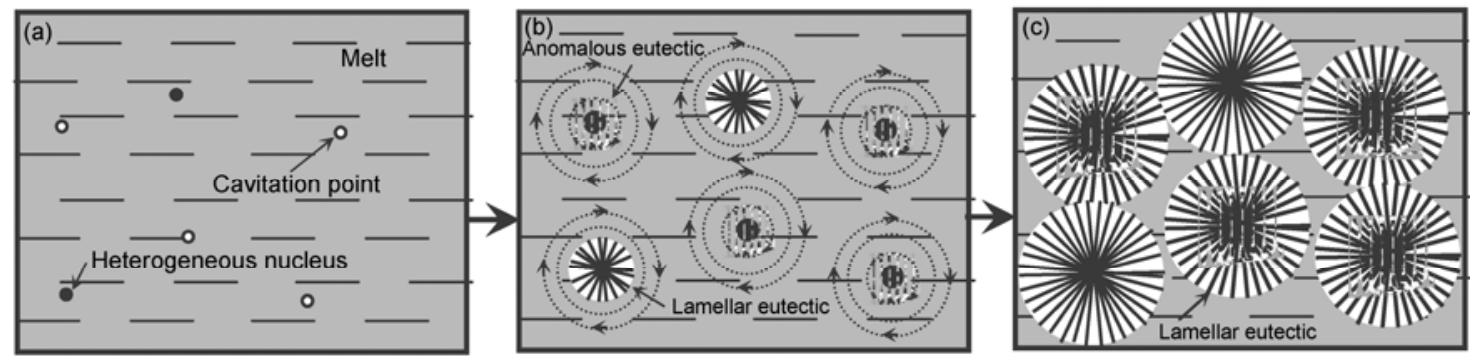

Figure 6 Schematics of nucleation and growth process of spherical eutectic cells. (a) Cavitation induced nucleation and ultrasound activated heterogeneous nucleus; (b) anomalous eutectic growth at large local undercooling and lamellar eutectic growth at small local undercooling; (c) two types of spherical eutectic cells. 
eutectic cell, as presented in Figure 4(d). A schematic diagram of the nucleation and growth process of the two kinds of spherical eutectic cells is shown in Figure 6. It should be noted that acoustic streaming also enhances solute interdiffusion between the two eutectic phases and increases the diffusion distances, resulting in larger interlamellar spacing in $\mathrm{Sn}-\mathrm{Pb}$ eutectic cells compared with the eutectic cells formed during static solidification.

\section{Conclusions}

The dynamic solidification of a $\mathrm{Sn}-38.1 \% \mathrm{~Pb}$ eutectic alloy within an ultrasonic field is investigated, and the main conclusions are as follows:

(1) The ultrasonic field significantly modifies the macrosegregation pattern in $\mathrm{Sn}-38.1 \% \mathrm{~Pb}$ alloy sample by extending the distribution range of the primary $(\mathrm{Sn})$ phase and shortening those of the $\mathrm{Sn}-\mathrm{Pb}$ eutectic and primary $(\mathrm{Pb})$ phases. Meanwhile, a "dendritic-equiaxed" structural transition occurs to the primary ( $\mathrm{Sn}$ ) phase, and its grain size is significantly reduced by the ultrasonic field. Once $H$ decrease to $\lambda / 2$ and $\lambda / 4$, macrosegregation is greatly suppressed or even eliminated by the ultrasound.

(2) There are two typical kinds of spherical eutectic cells formed within the ultrasonic field. One is composed of a lamellar eutectic structure growing epitaxially from the anomalous eutectic at the center of the cell, and the other is composed entirely of lamellar eutectic coming out from the center of the cell. During the eutectic growth process, radial symmetry of both the concentration and temperature fields induced by acoustic streaming ensures that the solid-liquid interface is symmetric in three dimensions.

(3) The bulk undercooling of the alloy melt is lower within the ultrasonic field than during static solidification. Two major factors, the higher local undercooling in the alloy melt caused by higher local pressure from the cavitiation effect, and the decrease of wetting angles between the crystal embryos and heterogeneous particles resulting from the propagation of the wave both stimulate crystal nucleation before large underocooling is achieved.

This work was supported by the National Natural Science Foundation of China (50971105). The authors are grateful to Mr. F. Wang, Dr. F. P. Dai and $D r$. W. L. Wang for their help during the experiment and for valuable discussions.

1 Abramov $\mathrm{O}$ V. Action of high intensity ultrasound on solidifying metal. Ultrasonics, 1987, 25: 73-82

2 Campell J. Effects of vibration during solidification. Int Mater Rev, 1981, 2: 71-103

3 Abramov V, Abramov O, Bulgakov V, et al. Solidification of aluminium alloys under ultrasonic irradiation using water-cooled resonator. Mater Lett, 1998, 37: 27-34

4 Han Y F, Shu D, Wang J, et al. Microstructure and grain refining performance of Al-5Ti-1B master alloy prepared under high-intensity ultrasound. Mater Sci Eng A, 2006, 430: 326-331

5 Jian X, Xu H, Meek T T, et al. Effect of power ultrasound on solidification of aluminum A356 alloy. Mater Lett, 2005, 59: 190-193

6 Zhai W, Hong Z Y, Xie W J, et al. Ternary eutectic growth of Ag$\mathrm{Cu}-\mathrm{Sb}$ alloy within ultrasonic field. Sci China Ser G-Phys Mech Astron, 2007, 50: 500-508

7 Li X T, Li T J, Li X M, et al. Study of ultrasonic melt treatment on the quality of horizontal continuously cast $\mathrm{Al}-1 \% \mathrm{Si}$ alloy. Ultrason Sonochem, 2006, 13: 121-125

8 Zhai W, Hong Z Y, Xie W J, et al. Solidification Characteristics of $\mathrm{Pb}-\mathrm{Sb}$ hypereutectic alloy within ultrasonic field. Chinese Sci Bull, 2007, 52: 844-848

9 Puga H, Teixeira J C, Barbosa J, et al. The combined effect of melt stirring and ultrasonic agitation on the degassing efficiency of $\mathrm{AlSi}_{9} \mathrm{Cu}_{3}$ alloy. Mater Lett, 2009, 63: 2089-2092

10 Su M X, Cai X S, Xu F, et al. The measurement of particle size and concentration in suspensions by ultrasonic attenuation (in Chinese). Acta Acustica, 2004, 29: 440-444

11 Liu X M, Gong Y Y, Hou X, et al. Influence of side ultrasonic treatment on Al-Si eutectic alloy (in Chinese). Chin J Nonferr Metal, 2007, 17: 307-312

12 Kurz W, Fisher D J. Fundamentals of Solidification. 3rd ed. Switzerland: Trans Tech Publications Ltd, 1998. 30-36

13 Brandes E A. Smithells Metals Reference Book. 6th ed. London: Butterworth Co Ltd, 1984. 8: 1-54

14 Dai F P, Xie W J, Wei B. Spherical ternary eutectic cells formed during free fall. Phil Mag Lett, 2009, 89: 170-177

15 Han X J, Wang N, Wei B. Rapid eutectic growth under containerless condition. Appl Phys Lett, 2002, 81: 778-780

16 Chow R, Blindt R, Chivers R, et al. A study on the primary and secondary nucleation of ice by power ultrasound. Ultrasonics, 2005, 43: $227-230$

Open Access This article is distributed under the terms of the Creative Commons Attribution License which permits any use, distribution, and reproduction in any medium, provided the original author(s) and source are credited. 